\title{
HAZARD ASSESSMENT OF LANDSLIDE DISASTER IN FUJIAN PROVINCE BASED ON FUZZY MATHEMATICS
}

\author{
Wang Jing-mei ${ }^{1,2,3}$, Gong A-du ${ }^{1,2,3}$, Chen Yan-ling ${ }^{1,2,3}$, Li Jing ${ }^{1,2,3}$, Zeng Ting-ting ${ }^{1,2,3}$ \\ 1. Key Laboratory of Environmental Change and Natural Disaster, MOE, Beijing Normal University, Beijing, 100875, China - \\ gad@bnu.edu.cn \\ 2. Beijing Key Laboratory of Environmental Remote Sensing and Digital City, Beijing Normal University, Beijing, 100875, China - \\ gad@bnu.edu.cn \\ 3. Faculty of Geographical Science, Beijing Normal University, Beijing, 100875, China - gad@ bnu.edu.cn
}

Commission ICWG III/IVa

KEY WORDS: Landslide; Hazard Assessment; Fuzzy Mathematics

\begin{abstract}
Landslide disasters are the most frequent geological disasters in Fujian Province. They are also the type of geological disasters that cause the most serious economic and population losses each year. This study uses the fuzzy mathematics method to carry on the hazard assessment of landslide disaster in Fujian Province, in order to explore the mechanism of the landslide disaster, and provides the reference for the construction land expansion in Fujian Province. The calculation results show that landslide disasters in Fujian Province have a high correlation with external forces, that is, long-term precipitation and short-term strong precipitation are likely to trigger landslide disasters. Among the internal stress factors, the correlation between the occurrence of landslides and slopes is the highest, and the probability of landslides occurs in areas with steep slopes. The evaluation results show that the areas with high landslide hazards are mainly distributed in the central region of Fujian Province. From the remote sensing images, it can be seen that most of the dangerous areas are in rapidly developing cities, and their vegetation coverage is relatively low, and the environment is greatly affected by humans.
\end{abstract}

\section{INTRODUCTION}

In Fujian Province, landslide disasters are the most frequent geological disasters in Fujian Province. They are also the type of disasters that cause the most serious economic and population losses each year (Huang C, 2000).

According to the disaster theory proposed by Shi Peijun (Shi Peijun, 1996), disaster risk assessment can be divided into hazard assessment and vulnerability assessment. The hazard assessment is to analyse the catastrophic environment and determine the probability of the disaster occurring in the area. Vulnerability assessment is the analysis of disaster entities, such as population and economy, to determine the probability of loss after disaster

The method of landslide hazard assessment can be divided into two categories. One is for a landslide disaster event, based on physical model and geological disaster process evaluation. However, this method is difficult to evaluate in a large space. The other is to use the characteristics of historical landslide hazards, based on statistical analysis theory, to macroscopically assess the risk of regional landslides. Logistic regression models (FC Dai et al., 2001; S Lee et al., 2007a; Lee S, Pradhan B, 2006b), fuzzy mathematical models (Murat Ercanoglu, 2001), support vector machines (M Marjanović et al., 2011; D Tien Bui et al., 2012; C $\mathrm{Xu}$ et al., 2012) and other models are used in disaster risk assessment. The most widely used model is the Logistic regression model.

Some scholars compare various types of models. Hu Deyong $(\mathrm{Hu}$ Deyong et al., 2007) proposed that the SVM model is suitable for small sample size. Si Kangping (Si Kangping., 2008) proposed that logistic regression models can select variables that are statistically significant compared with GAM (generalized additive model) models and CART (classification and regression tree) models. However, the relationship between impact factors and landslide hazards in reality is complex and non-linear. The results of Logistic regression model will have errors.

Taking into account the large number of landslide hazards acquired, fuzzy mathematics (statistical model) was used in this study. In order to ensure that the factors are independent of each other, the correlation coefficient method is used to extract and establish the index system, and the correlation coefficient is used as the index weight. The frequency ratio model is used to calculate the degree of membership. Evaluation of landslide hazards in the study area is based on the principle of maximum degree of membership.

\section{STUDY AREA}

Fujian Province is located on the south-eastern coast of China and is located at longitude $115^{\circ} 50^{\prime}-120^{\circ} 44^{\prime}$ and latitude $23^{\circ} 31^{\prime}$ $28^{\circ} 19^{\prime}$ (Figure 1). The elevation of the area is $5-2200 \mathrm{~m}$, and its mountainous area accounts for more than $80 \%$ of the province. The province has a high proportion of vegetation coverage. The average annual rainfall is $1100-2100 \mathrm{~mm}$, and the annual rainfall is concentrated in March-September, with the most precipitation in May, June and August. Heavy rainfall is often accompanied by the typhoon. Recently, it has developed rapidly. The population has been concentrated mainly in the eastern coastal cities; cities have expanded along the mountains. Rivers, highways and railways have been established in every city. At the same time, they have also affected the natural ecology.

\section{DATA USED}

\subsection{Landslide inventory}

Landslide inventory data is the basis for landslide hazard assessment and can be used to explore the relationship between landslide hazards and environmental factors. This study used the results of the 2013 Survey of Geological Hazards in Counties (Cities) of Fujian Province to evaluate the landslide survey sites 
after they were spatialized. A total of 6912 landslide sites were found in the study area, and the data sets were divided into training sets and test sets. Among them, $70 \%$ of the dataset is used to train the model, and $30 \%$ of the dataset is used for verification ((Figure 1). Both datasets are randomly generated by ArcGIS software.

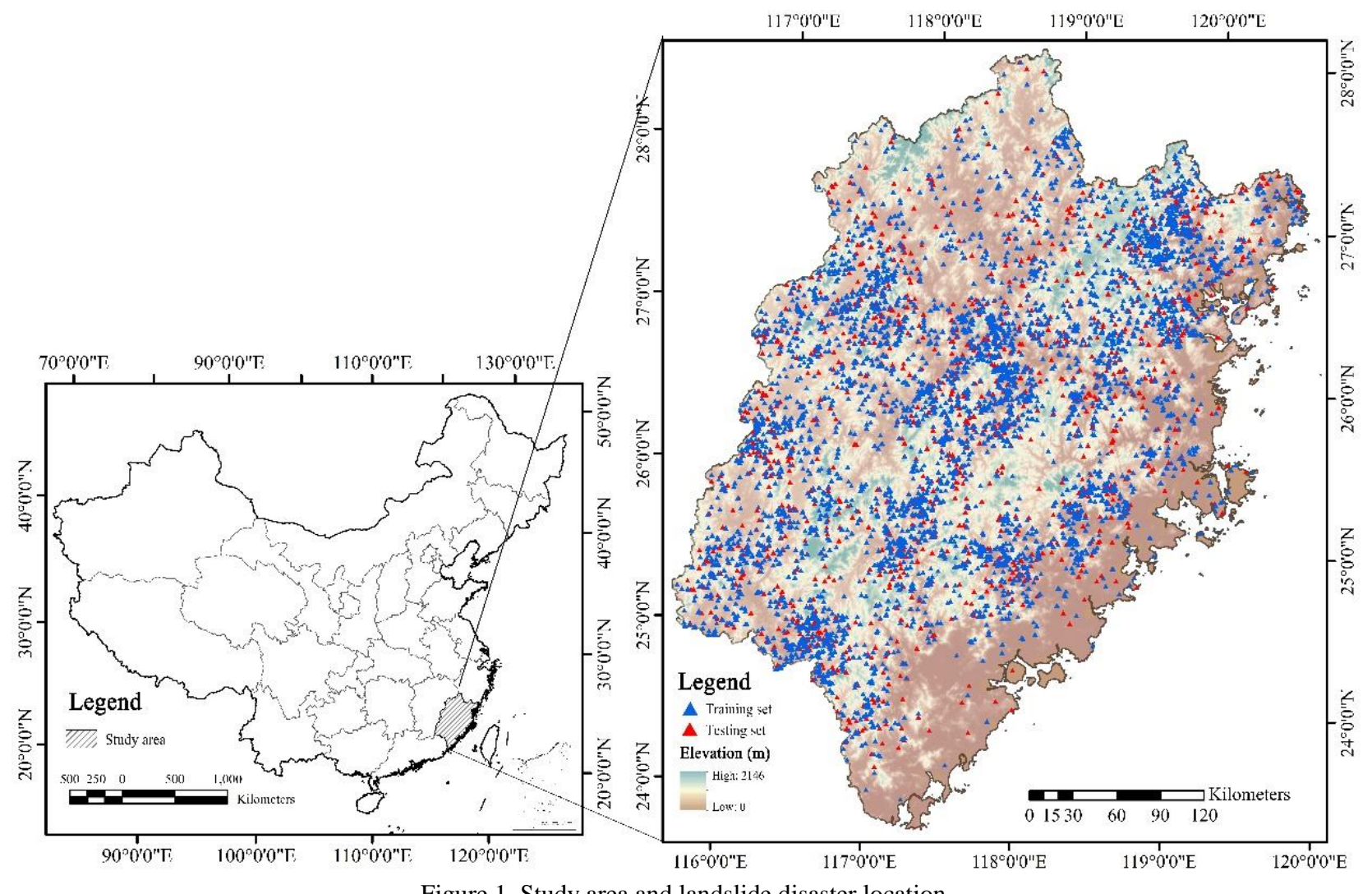

Figure 1. Study area and landslide disaster location

\subsection{Influencing factors}

This study divides the influencing factors that affect landslides into two categories, environmental factors and disaster-causing factors. The environmental factors are the environment in which the landslide body is located, such as slope, elevation, and vegetation index. The disaster-causing factors refer to the factors that cause landslide disasters. Although Fujian Province is on the fault zone, and earthquakes have occurred in recent years (monitored by the Seismological Bureau of Fujian Province), the magnitude is small and it is not enough to generate landslides. According to the results of the Survey of Geological Hazards in Counties (Cities) of Fujian Province, landslide disasters in Fujian Province were mostly caused by heavy rainfall. Therefore, this study selected the maximum rainfall in 3 days, the longest continuous rainfall period and the annual average precipitation as the disaster-causing factors (Table 1).

3.2.1 Slope gradient: Slope is an important factor influencing slope stability. As the slope gradient increases, the greater the sliding force of the slope, the lower the anti-sliding ability of the soil. From the point of view of the landslide frequency distribution at the place where the disaster occurred, in general, the higher the slope, the higher the frequency of landslides. Statistics show that $70 \%$ of landslide disasters are concentrated between $20^{\circ}-50^{\circ}$. The area above $50^{\circ}$ is mostly rock, and its stability is better than that of soil
3.2.2 Elevation: There is a certain correlation between elevation and slope failure, such as different vegetation types and vegetation coverage in different elevation ranges, and different effects on soil and water conservation; and in different elevation ranges, the temporary space of slope sliding is different, and the intensity of human activities is greatly different. Statistical results show that more than $50 \%$ of landslides occur in the area $200 \mathrm{~m}$ to $500 \mathrm{~m}$ above sea level.

3.2.3 Vegetation cover: Most of the landslide disasters in Fujian are caused by heavy rain, while the vegetation has a buffer effect on rain erosion. At the same time, the root system of trees has a strengthening effect on the soil. Therefore, the vegetation coverage is negatively correlated with the occurrence of landslides. Due to the high vegetation coverage rate in Fujian, NDVI (Normalized Difference Vegetation Index) will be oversaturated. The study uses the EVI (Enhanced Vegetation Index) vegetation index for evaluation. EVI's formula is:

$$
E V I=2.5 \times \frac{\rho_{N I R}-\rho_{R}}{\rho_{N I R}+6.0 \rho_{R}-7.5 \rho_{B}+1}
$$

where

$$
\begin{aligned}
& \rho_{N I R}=\text { Near infrared reflectance } \\
& \rho_{R}=\text { Red band reflectance } \\
& \rho_{B}=\text { Blue band reflectance }
\end{aligned}
$$

Statistics show that $70 \%$ of landslide disasters occur in the region with index between $0-0.5$ 


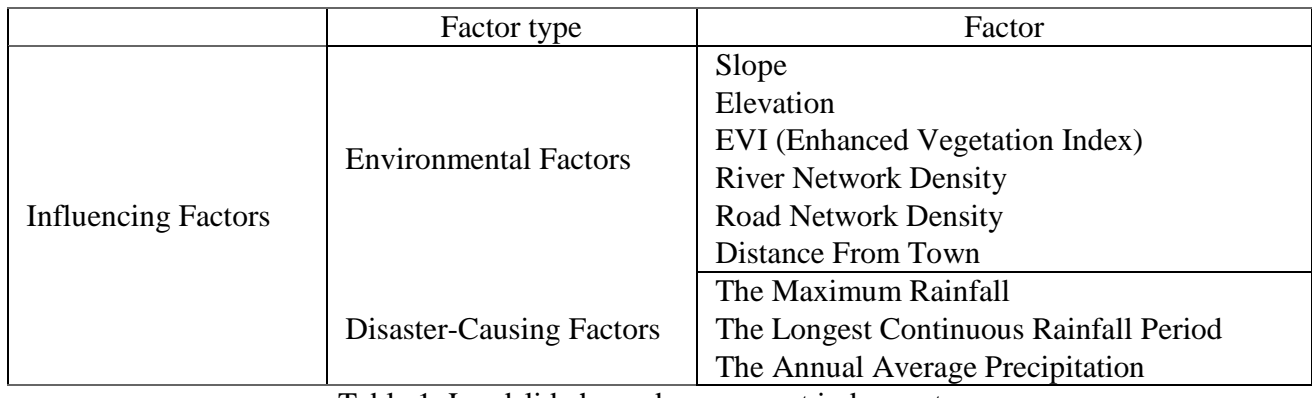

Table 1. Landslide hazard assessment index system

3.2.4 River Network Density: Under the erosion of the river, the soil is relatively soft. When heavy rain occurs, it is prone to landslides. The study uses river network density $\left(\right.$ per $\left.\mathrm{km}^{2}\right)$ for evaluation. The statistical results show that $45 \%$ of landslide disasters are distributed at a river network density of 5-10.

3.2.5 Human activity: The construction of roads and houses around the hills sometimes cut natural slopes, resulting in unstable slopes and landslides. The study uses the distance to the city and the density of the road network for assessment. The statistical results show that $70 \%$ of landslide disasters are distributed in the road network density of $7.5-16 ; 72 \%$ of the landslide disasters are located at $4-12 \mathrm{~km}$ from the city.
3.2.6 Disaster-causing factors: Short-term heavy rainfall has a strong scouring effect on the soil, causing the soil to slide downwards, resulting in landslide hazards. Prolonged rainfall increases soil moisture. On the one hand, the total amount of soil is increased, and on the other hand, the slope becomes smooth, which easily leads to landslide disasters. The study used the rainfall statistics from 1999 to 2016 to conduct statistics on the daily rainfall at various weather stations in Fujian Province. The longest continuous rainfall time, maximum daily rainfall in 3 days, and annual average rainfall are used in the evaluation.

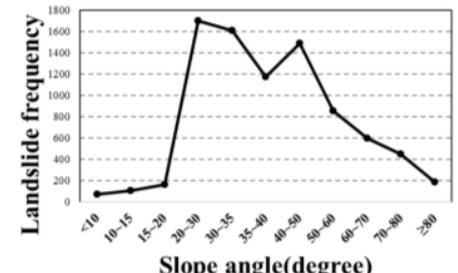

Slope angle(degree)

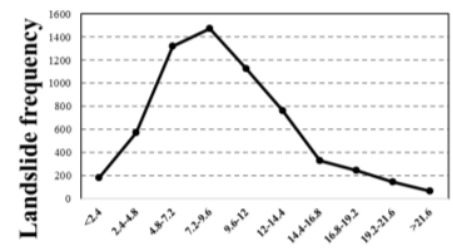

River Network Density (per $\left.\mathbf{k m}^{2}\right)$

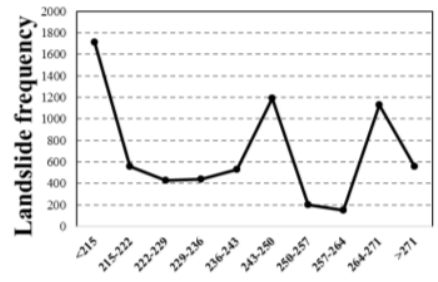

The Maximum Daily Rainfall (mm)

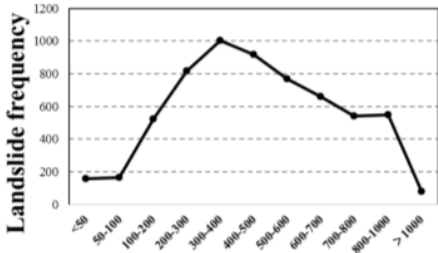

Elevation(m)

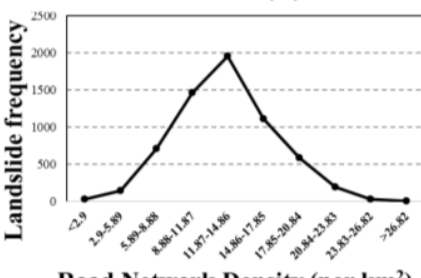

Road Network Density (per $\mathrm{km}^{2}$ )

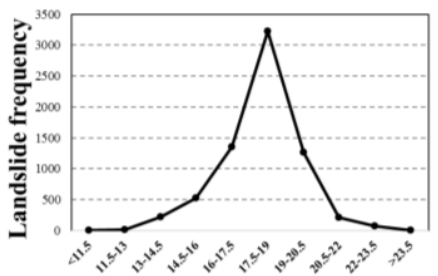

The Longest Continuous Rainfall Period (d)

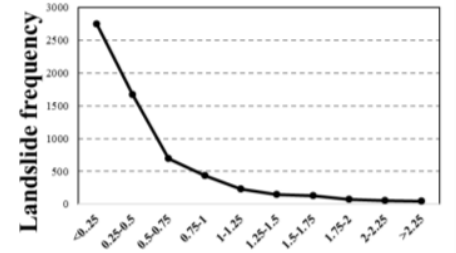

RVI

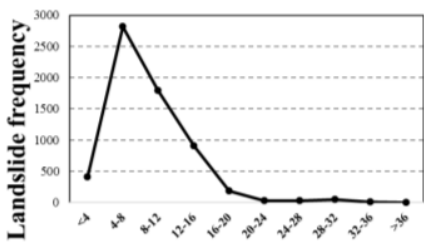

Distance From Town (km)

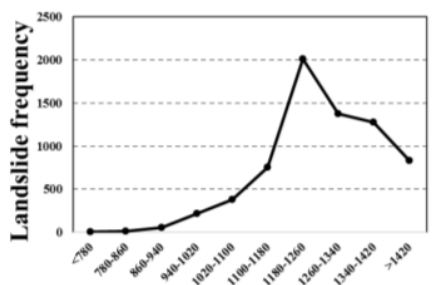

The Annual Average Precipitation ( $\mathrm{mm}$ )

Figure 2. Statistical relationship between influencing factors and landslide hazard

\section{MEHODOLOGY}

\subsection{Selection of index based on correlation analysis}

Because the factors are not independent, the correlation coefficient is calculated to analyse each correlation. The correlation coefficient calculation method is

$$
r_{i j}=\frac{\sum_{k=1}^{n}\left(x_{k i}-\overline{x_{i}}\right)\left(x_{k j}-\overline{x_{j}}\right)}{\sqrt{\sum_{k=1}^{n}\left(x_{k i}-\overline{x_{i}}\right)^{2} \sum_{k=1}^{n}\left(x_{k j}-\overline{x_{j}}\right)^{2}}}
$$

The correlation coefficient between each factor and landslide disaster density was calculated. The results are used to select index that are closely related to disasters. The correlation coefficient is normalized to obtain the weight of each factor in the fuzzy evaluation.

According to the correlation between disaster density and various factors, factors with a correlation coefficient greater than 0.15 were selected to form an index system. Table 2 shows that the correlation coefficient between the road network density and the distance from the town is large. Therefore, the two were evaluated as comprehensive factors. 


\begin{tabular}{|c|c|c|c|c|c|c|c|c|c|}
\hline & Slope & EVI & $\begin{array}{l}\text { Road } \\
\text { Network } \\
\text { Density }\end{array}$ & $\begin{array}{l}\text { River } \\
\text { Network } \\
\text { Density }\end{array}$ & $\begin{array}{l}\text { Distance } \\
\text { From } \\
\text { Town }\end{array}$ & Elevation & $\begin{array}{l}\text { Longest } \\
\text { Rainfall } \\
\text { Period }\end{array}$ & $\begin{array}{l}\text { The } \\
\text { Maximum } \\
\text { Rainfall }\end{array}$ & $\begin{array}{l}\text { The Annual } \\
\text { Average } \\
\text { Precipitation }\end{array}$ \\
\hline Slope & 1.00 & & & & & & & & \\
\hline EVI & 0.035 & 1.00 & & & & & & & \\
\hline Road Network Density & -0.140 & 0.010 & 1.00 & & & & & & \\
\hline River Network Density & 0.105 & -0.008 & 0.092 & 1.00 & & & & & \\
\hline Distance From Town & -0.233 & -0.010 & 0.708 & -0.026 & 1.00 & & & & \\
\hline Elevation & 0.373 & -0.021 & -0.257 & 0.124 & -0.369 & 1.00 & & & \\
\hline $\begin{array}{l}\text { The Longest Continuous } \\
\text { Rainfall Period }\end{array}$ & & & & & & & 1 & & \\
\hline The Maximum Rainfall & & & & & & & 0.328 & 1 & \\
\hline $\begin{array}{l}\text { The Annual Average } \\
\text { Precipitation }\end{array}$ & & & & & & & 0.106 & 0.286 & 1 \\
\hline Landslide & 0.278 & 0.184 & 0.204 & 0.104 & 0.223 & 0.119 & 0.844 & 0.818 & 0.538 \\
\hline
\end{tabular}

Table 2. Correlation coefficient calculation result table

4.1.1 Disaster-causing factors: Short-term heavy rainfall has a strong scouring effect on the soil, causing the soil to slide downwards, resulting in landslide hazards. Prolonged rainfall increases soil moisture. On the one hand, the total amount of soil is increased, and on the other hand, the slope becomes smooth, which easily leads to landslide disasters. The study used the rainfall statistics from 1999 to 2016 to conduct statistics on the daily rainfall at various weather stations in Fujian Province and use Kriging interpolation to perform surface interpolation. The longest continuous rainfall time, maximum daily rainfall in 3 days, and annual average rainfall are used in the evaluation of landslide disasters.

\subsection{Fuzzy mathematic evaluation}

The statistical results show that the occurrence of landslide hazards does not have a linear relationship with each factor. Therefore, the fuzzy mathematics method was chosen to evaluate landslide hazards.

4.2.1 Weight calculation: Using $70 \%$ of the disaster point data, the correlation coefficient between each factor and landslide disaster density was calculated. The results are used to screen indicators that are closely related to disasters. The correlation coefficient is normalized to obtain the weight of each factor in the fuzzy evaluation.
If there is a high correlation coefficient between multiple factors and both are associated with a disaster, the two factors are combined into a single comprehensive factor. Take the average of the correlation coefficients of multiple factors and normalize the results with other factors as the weight of the synthesis factor.

4.2.2 Membership calculation: The disaster density is divided into four sections, which are dangerous, more dangerous, safer, and safer. Based on the frequency ratio model, the ratio of the area of each factor to the total area of the hazard level is calculated for each level of disaster density (Lee S, Sambath T, 2006; Lee S, Pradhan B, 2007). Its calculation formula is

$$
F R=\frac{\frac{N p\left(L X_{i}\right)}{\sum_{i=1}^{m} N p\left(L X_{i}\right)}}{\frac{N p\left(X_{j}\right)}{\sum_{j=1}^{m} N p\left(X_{j}\right)}}
$$

After standardizing the proportions of each category, it is used as the numerical value of the degree of membership of the segment factor at different levels of risk.

Finally, the risk grade of landslides in the study area was divided according to the principle of maximum affiliation.

\begin{tabular}{|c|c|c|c|c|c|c|c|}
\hline \multirow{2}{*}{ Index Type } & \multirow{2}{*}{ Index } & \multirow{2}{*}{ Weight } & \multirow{2}{*}{ Segment } & \multicolumn{4}{|c|}{ Membership Degree Value } \\
\hline & & & & $\mathrm{I}$ & II & III & $\mathrm{V}$ \\
\hline \multirow{15}{*}{$\begin{array}{l}\text { Environmental } \\
\text { Factors }\end{array}$} & \multirow{9}{*}{$\begin{array}{c}\text { Comprehensive Index: } \\
\text { Distance From Town } \\
\text { (D)\& Road Network } \\
\text { Density (R) }\end{array}$} & \multirow{9}{*}{0.355} & $\mathrm{D}<4 \mathrm{~km} ; \mathrm{R}<7.5$ & 0.33 & 0.25 & 0.25 & 0.17 \\
\hline & & & $\mathrm{D}<4 \mathrm{~km} ; \mathrm{R}<16$ & 0.06 & 0.28 & 0.22 & 0.44 \\
\hline & & & $\mathrm{D}<4 \mathrm{~km} ; \mathrm{R} \geq 16$ & 0.20 & 0.27 & 0.20 & 0.33 \\
\hline & & & $\mathrm{D}<12 \mathrm{~km} ; \mathrm{R}<7.5$ & 0.15 & 0.15 & 0.20 & 0.50 \\
\hline & & & $\mathrm{D}<12 \mathrm{~km} ; \mathrm{R}<16$ & 0.06 & 0.19 & 0.38 & 0.38 \\
\hline & & & $\mathrm{D}<12 \mathrm{~km} ; \mathrm{R} \geq 16$ & 0.27 & 0.36 & 0.27 & 0.09 \\
\hline & & & $\mathrm{D} \geq 12 \mathrm{~km} ; \mathrm{R}<7.5$ & 0.41 & 0.35 & 0.12 & 0.12 \\
\hline & & & $\mathrm{D} \geq 12 \mathrm{~km} ; \mathrm{R}<16$ & 0.50 & 0.20 & 0.15 & 0.15 \\
\hline & & & $\mathrm{D} \geq 12 \mathrm{~km} ; \mathrm{R} \geq 16$ & 0.45 & 0.27 & 0.18 & 0.09 \\
\hline & \multirow{3}{*}{ Slope } & \multirow{3}{*}{0.396} & $<20^{\circ}$ & 0.15 & 0.31 & 0.31 & 0.23 \\
\hline & & & $<47.2^{\circ}$ & 0.06 & 0.31 & 0.25 & 0.38 \\
\hline & & & $\geq 47.2^{\circ}$ & 0.53 & 0.29 & 0.12 & 0.06 \\
\hline & \multirow{3}{*}{ RVI } & \multirow{3}{*}{0.249} & $<1.5$ & 0.40 & 0.33 & 0.20 & 0.07 \\
\hline & & & $<1.75$ & 0.06 & 0.17 & 0.33 & 0.44 \\
\hline & & & $\geq 1.75$ & 0.33 & 0.33 & 0.17 & 0.17 \\
\hline
\end{tabular}

Table 3. Membership of influencing factors according to the frequency ratio model 
The International Archives of the Photogrammetry, Remote Sensing and Spatial Information Sciences, Volume XLII-3, 2018 ISPRS TC III Mid-term Symposium "Developments, Technologies and Applications in Remote Sensing", 7-10 May, Beijing, China

\begin{tabular}{|c|c|c|c|c|c|c|c|}
\hline \multirow{2}{*}{ Index Type } & \multirow{2}{*}{ Index } & \multirow{2}{*}{ Weight } & \multirow{2}{*}{ Segment } & \multicolumn{4}{|c|}{ Membership Degree Value } \\
\hline & & & & $\mathrm{I}$ & II & III & $\mathrm{V}$ \\
\hline \multirow{10}{*}{$\begin{array}{c}\text { Disaster- } \\
\text { Causing Factors }\end{array}$} & \multirow{3}{*}{$\begin{array}{c}\text { The Longest } \\
\text { Continuous Rainfall } \\
\text { Period }\end{array}$} & \multirow{3}{*}{0.342} & $<17 d$ & 0.27 & 0.45 & 0.18 & 0.09 \\
\hline & & & $<19.8 d$ & 0.20 & 0.33 & 0.40 & 0.07 \\
\hline & & & $\geq 13.7 \mathrm{~d}$ & 0.13 & 0.13 & 0.13 & 0.63 \\
\hline & \multirow{4}{*}{$\begin{array}{c}\text { The Maximum Rainfall } \\
\text { in } 3 \text { Days }\end{array}$} & \multirow{4}{*}{0.415} & $<225 \mathrm{~mm}$ & 0.17 & 0.17 & 0.25 & 0.42 \\
\hline & & & $<255 \mathrm{~mm}$ & 0.14 & 0.36 & 0.21 & 0.29 \\
\hline & & & $<279 \mathrm{~mm}$ & 0.21 & 0.11 & 0.21 & 0.47 \\
\hline & & & $\geq 279 \mathrm{~mm}$ & 1.00 & 0.00 & 0.00 & 0.00 \\
\hline & \multirow{3}{*}{$\begin{array}{c}\text { The Annual Average } \\
\text { Precipitation }\end{array}$} & \multirow{3}{*}{0.243} & $<1660.5 \mathrm{~mm}$ & 0.57 & 0.14 & 0.00 & 0.29 \\
\hline & & & $<2325 \mathrm{~mm}$ & 0.09 & 0.18 & 0.64 & 0.09 \\
\hline & & & $\geq 2325 \mathrm{~mm}$ & 0.11 & 0.26 & 0.16 & 0.47 \\
\hline
\end{tabular}

Table 3. (Continued)

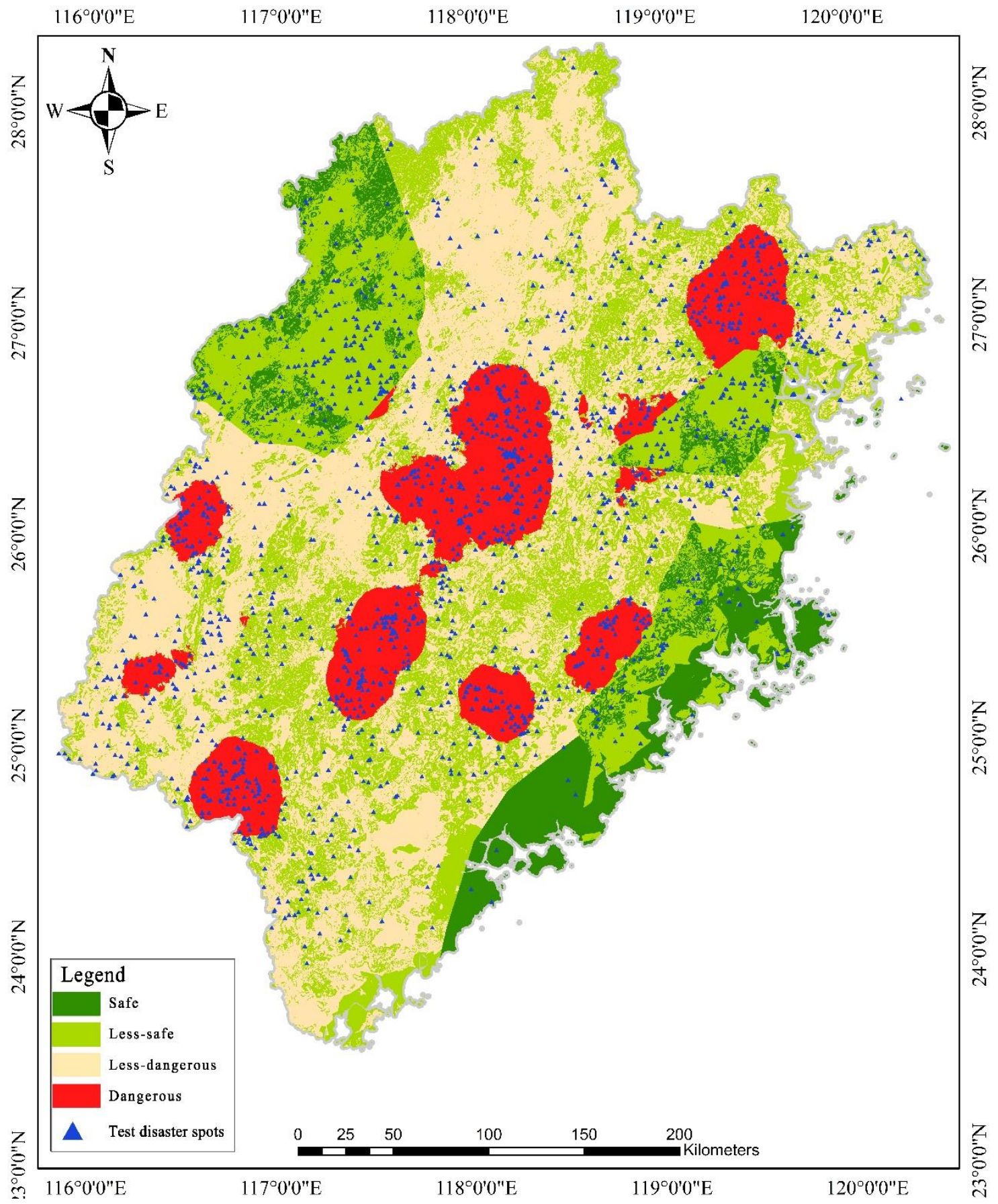

Figure 3. Landslide hazard assessment result in Fujian province 


\section{RESULTS}

\subsection{Correlation analysis}

5.1.1 Disaster-causing factors: From the results of correlation coefficient calculation, we can see that the disastercausing factors are more relevant than the disaster environment factors. This means that areas with frequent heavy rainfall are more likely to trigger landslide disasters.

Among the three factors, the maximum precipitation within 3 days is most relevant to landslide hazards. This shows that landslides are more prone to occur than under short-term rainfall. Short-term heavy rainfall means that when the disaster occurs, the emergency time is short, and higher demands are made on disaster relief work. Therefore, in the disaster prevention and reduction project, it is necessary to strengthen the forecast of heavy rainfall and to evacuate people living in high-risk areas in time.

5.1.2 Environmental factors: Among the environmental factors, the most closely related to landslides is slope, followed by human activities. In fact, due to the wide distribution of hills in Fujian Province, artificial slopes will be imposed on the mountains during the construction of buildings and roads. As a result, the slope increases and the slope becomes unstable. Therefore, in the prevention of landslide hazards, attention should be paid to the protection of natural slopes.

\subsection{Hazard assessment analysis}

As shown in Figure 3, the hazardous areas are mainly distributed in the central region of Fujian Province, followed by the northwestern mountainous regions and the south-eastern coastal regions.

Statistics shows that $37 \%$ landslide spots belong to dangerous level; $45 \%$ belong to less-dangerous level; $17 \%$ belong to lesssafe level and $1 \%$ belong to safe level. Thus, the evaluation results are credible.

5.2.1 Southeast coastal area: Landslides occur less frequently in the south-eastern coastal areas because of the lack of mountainous distribution. However, the south-eastern coastal area has a high population density and there are many buildings. In addition, heavy rainfall in Fujian Province mostly comes from typhoon disasters, and southeast coastal areas are most affected by typhoon disasters. When a landslide disaster occurs, it can easily cause huge economic losses. Therefore, the southeast coastal areas should strengthen the protection of buildings and personnel.

5.2.2 Central area: The central area is the region with the largest landslide probability, and it is also the region with the fastest economic development in Fujian Province. It can be known from remote sensing images in some areas that vegetation coverage is sparse in most dangerous areas and there are many industrial and mining land distributions within the area. Compared with the coastal areas, the mountainous area in the central area is larger; compared with the north-western mountainous region, the frequency of short-term strong rainfall is higher. Therefore, we must pay attention to the balance between economic development and ecological protection, and reinforce or repair the slopes that have been destroyed.
5.2.3 Northwest mountain area: The north-western region of Fujian Province belongs to the Wuyi Mountain Range, with large mountainous areas and some natural reserves. The area has high vegetation coverage and strong water and soil conservation. Being far away from the coastline makes the area less affected by typhoons, and the probability of occurrence of heavy rainfall is smaller than in the central and southeast regions. However, the economic conditions in the mountains are poor, and local demand for construction land is high. Under the premise of protecting the ecological environment, the focus of development should be on excavating local land with low efficiency and improving the efficiency of land use.

\section{REFERENCES}

Dai F C, Lee C F, Li J, et al. Assessment of landslide susceptibility on the natural terrain of Lantau Island, Hong Kong[J]. Environmental Geology, 2001, 40(3), pp. 381-391.

Dai F, Lee C F, Wang S. Analysis of rainstorm-induced slidedebris flows on natural terrain of Lantau Island, Hong Kong[J]. Engineering Geology, 1999, 51(4), pp. 279-290.

De-Yong H U, Jing L I, Chen Y H, et al. GIS-based Landslide Spatial Prediction Methods,a Case Study in Cameron Highland,Malaysia[J]. Journal of Remote Sensing, 2007, 11(6), pp.852-859.

Huang C. The Present Situation Of Geological Disasters And Control Measures In Fujian Province[J]. Journal of Geological Hazards \& Environment Preservation, 2000.

Kangping S I, Yuan T, Wang D, et al. Comparison of Three Statistical Methods on Landslide Susceptibility Analysis:A Case Study of Shenzhen City[J]. Acta Scientiarum Naturalium Universitatis Pekinensis, 2008, 850(4), pp. 639-646.

Lee S, Pradhan B. Landslide hazard mapping at Selangor, Malaysia using frequency ratio and logistic regression models[J]. Landslides, 2007a, 4(1), pp. 33-41.

Lee S, Sambath T. Landslide susceptibility mapping in the Damrei Romel area, Cambodia using frequency ratio and logistic regression models[J]. Environmental Geology, 2006b, 50(6), pp. 847-855.

Marjanović M, Kovačević M, Bajat B, et al. Landslide susceptibility assessment using SVM machine learning algorithm[J]. Engineering Geology, 2011, 123(3), pp. 225-234.

Shi P J. Theory and practice of disaster study[J]. Journal of Natural Disasters, 1996, 5(4), pp. 6-17.

Tien Bui D, Pradhan B, Lofman O, et al. Landslide susceptibility assessment in vietnam using support vector machines, decision tree, and Naive Bayes Models[J]. Mathematical Problems in Engineering, 2012, 2012.

$\mathrm{Xu} \mathrm{C}$, Dai F, Xu X, et al. GIS-based support vector machine modeling of earthquake-triggered landslide susceptibility in the Jianjiang River watershed, China[J]. Geomorphology, 2012, 145, pp. 70-80. 